Research Article

\title{
Temperature Load Parameters and Thermal Effects of a Long-Span Concrete-Filled Steel Tube Arch Bridge in Tibet
}

\author{
Tuo Shi $\left(\mathbb{D},{ }^{1}\right.$ Jielian Zheng, ${ }^{1,2,3}$ Nianchun Deng $\mathbb{C}^{1,2,3}$ Zheng Chen, ${ }^{1,2,3}$ Xiao Guo, ${ }^{1,2,3}$ \\ and Shi Wang $\mathbb{D}^{4}$ \\ ${ }^{1}$ College of Civil Engineering and Architecture, Guangxi University, Nanning 530004, China \\ ${ }^{2}$ Guangxi Special Geological Highway Safety Engineering Technology Research Center, Guangxi University, Nanning 530004, \\ China \\ ${ }^{3}$ Guangxi Long-span Arch Bridges Engineering Technology Center, Guangxi University, Nanning 530004, China \\ ${ }^{4}$ Tibet Railway Construction Co. Ltd., Lasa 851400, China \\ Correspondence should be addressed to Nianchun Deng; dengnch@gxu.edu.cn
}

Received 5 November 2019; Revised 13 January 2020; Accepted 22 January 2020; Published 19 February 2020

Academic Editor: Luigi Nicolais

Copyright (C) 2020 Tuo Shi et al. This is an open access article distributed under the Creative Commons Attribution License, which permits unrestricted use, distribution, and reproduction in any medium, provided the original work is properly cited.

\begin{abstract}
Zangmu Bridge is a concrete-filled steel tube (CFST) arch bridge along the Sichuan-Tibet railway in Tibet, with a main span of $430 \mathrm{~m}$. Owing to the unique temperature conditions in Tibet, there have been no large-scale experimental studies on the thermal load design of CFST bridges in this area. Therefore, to determine the thermal load calculation parameters and thermal effects of Zangmu Bridge, a long-term continuous field test was conducted to measure the temperature variations in a test arch with the same pipe diameter. The test results were then compared with current design specifications and relevant literature. Finally, the thermal effects in a CFST arch bridge were analysed using the finite element method. According to the results, the following recommendations were made: (1) the average temperature of concrete in the pipe after the formation of concrete strength should be used to calculate the closure temperature of CFST arch bridges in Tibet; however, the standard calculation formula was still applicable; (2) the daily average temperature in extreme weather should be taken as the maximum and minimum effective temperature; (3) we presented recommended values for the influence range and gradient temperature for a single large-diameter pipe; and (4) a refined finite element model that included the arch base should be used to verify the temperature effects during bridge design.
\end{abstract}

\section{Introduction}

Concrete-filled steel tube (CFST) arch bridges have significant economic advantages at certain spans $[1,2]$. Owing to an improvement of key construction technology and the good adaptability of CFST arch bridges [3], they have been vital in the construction of the Sichuan-Tibet railway in Tibet, China. However, the characteristics of a bridge's temperature field vary both temporally and spatially and are influenced by several factors. For example, clear regional differences are observed, particularly in Tibet. As temperature changes in the composite arch ribs of CFST arch bridges lead to temperature stress, an arch rib with a large diameter in a long-span arch bridge will exhibit unique temperature ranges and trends [4].
The parameters required to calculate the design temperature load include the maximum effective temperature, minimum effective temperature, closure temperature, and gradient temperature. During the construction of a CFST arch bridge, the temperature field is affected by several factors. Therefore, defining the calculation parameters under continuous and irregular temperature changes is a complex problem. The China Technical Code for CFST Arch Bridges (GB 50923-2013) [5] (hereafter referred to as "Code 1") and the China Highway Design Code for CFST Arch Bridges (JTGTD65-06-2015) [6] (hereafter referred to as "Code 2") include specific provisions for the values of maximum and minimum effective temperature, closure temperature, and gradient temperature. 
Several researchers have studied the calculation parameters for temperature load in CFST arch bridges. For example, Chen et al. [7, 8] first proposed a concept for calculating the closure temperature and suggested that the daily average temperature should be employed as the effective temperature. Lin et al. [9] conducted large-scale model tests and suggested that the structural temperature, one of the calculation indexes of closure temperature, could be represented by the average temperature of the seven days after arch rib pouring. Huang et al. [10] proposed using the average temperature of the 28 days after concrete pouring plus $2.5-4.5^{\circ} \mathrm{C}$ as the calculated closure temperature for dumbbell shaped arches. Moreover, they employed the local maximum air temperature minus $2^{\circ} \mathrm{C}$ as the maximum effective temperature and the daily average temperature of the coldest day as the minimum effective temperature. Liu et al. [11] suggested using the average temperature of the 28 days after pouring plus $3-5^{\circ} \mathrm{C}$ as the closure temperature and the local air temperature pole as the effective temperature. Chen et al. [12] analysed several bridges in China and concluded that the formula used in Code 2 was applicable for bridges throughout the country. Yang et al. [13] obtained a numerical calculation formula for closure temperature through tests and calculation analyses of actual bridges. Jiang et al. [14], Chen and Li [15], and Yan [16] studied the gradient temperature of CFST specimens, and they gave recommendations for the gradient temperature. However, all the aforementioned studies were limited by the small size of the test components, a lack of consideration of regional climate characteristics, and the absence of engineering verification. Moreover, because the thermal load calculation parameters included in Chinese design codes are too conservative, the resulting thermal effects were relatively large.

Owing to the unique climate in Tibet, which is characterised by low temperatures and large temperature differences, there have been no large-scale experimental studies on the thermal load design of CFST bridges in this area. Therefore, this study analyses the design local thermal load calculation parameters and thermal effects for Zangmu Bridge in the Lalin section of the Sichuan-Tibet railway by constructing a test arch with the same diameter at the bridge site. Long-term continuous field tests are then conducted to measure the temperature of the test arch. This research aims to provide a basis for the design temperature load parameters of CFST arch bridges under the unique temperature conditions of Tibet, as well as a reference for the corresponding Chinese design codes.

\section{Materials and Methods}

First, the closure temperature, effective temperature, and gradient temperature of the CFST arch bridge were measured. The finite element calculation was then conducted using the experimentally determined temperature parameters to obtain a value for the temperature effect, which was compared with the Chinese standard.

Zangmu Bridge in the Lalin section of the Sichuan-Tibet railway was used as the object of this study. The bridge is a half-through type CFST arch bridge with a span of $430 \mathrm{~m}$ located in Lasui Township, Jiacha County, Shannan City, Tibet. The mechanical and geometrical properties of Zangmu Bridge are shown in Table 1.

The test arch was installed near the bridge site, replicating a $75 \mathrm{~m}$ section of the bridge near the crown, extending from the vault to the arch foot of the bridge. The horizontal length of the test arch is $75 \mathrm{~m}$, arch height is $11.25 \mathrm{~m}$, pipe diameter is $1.6 \mathrm{~m}$, and wall thickness is $20 \mathrm{~mm}$. Q345 steel and C60 concrete were used in the test arch. The design parameters and a photograph of the test arch are shown in Figures 1 and 2. Thermistor-type temperature sensors were used in the test, which were attached to cross fixed highstrength insulated steel wire rope. A wireless temperature acquisition system was utilized, with the acquisition frequency set to 1 reading every $10 \mathrm{~min}$. The length of continuous observations was one year, from May 2018 to May 2019. The layout of the measurement points is shown in Figure 3 (external sensor for outside air temperature not shown).

The results obtained for closure temperature, effective temperature, and gradient temperature were compared with the Chinese standards and existing literature, resulting in a recommendation for the temperature calculation parameters that best represent the situation in Tibet. The recommended temperature parameters and the temperature parameters in the Chinese codes were then used in a finite element model to calculate the temperature effect. Further, the conventional and refined models would be established. The conventional model was the finite element model used in bridge design of China, including arch rib, suspender, bridge deck system, and other structures. The fine model was based on the conventional model and considers the arch base. The temperature effects calculated by different models for the same temperature parameters were analysed and compared with the calculation results for different temperature parameters within the same model.

\section{Results and Discussion}

3.1. Closure Temperature. When calculating the temperature change, the average temperature value of the section when the concrete in the pipe formed strength and the temperature value when the internal force of the corresponding section was zero shall be taken as the reference temperature. The reference temperature should be called "closure temperature." Continuous observations were made at each measurement point after the concrete was poured. A separate sensor (point 0 ) was placed outside the test section to simultaneously measure the air temperature. The recorded changes in temperature over time of representative measuring point are shown in Figure 4. The initial casting temperature of the concrete was $29.9^{\circ} \mathrm{C}$. After $5 \mathrm{~h}$, the temperature rose rapidly, reaching a peak hydration heat of $96.7^{\circ} \mathrm{C}$ after $29 \mathrm{~h}$, corresponding to an increase in temperature of $66.8^{\circ} \mathrm{C}$. Hydration heating was observed for 8 days, with a maximum temperature difference in the test section of $42.4^{\circ} \mathrm{C}$, after which the temperature dropped to the ambient level. After 8 days, the temperature of the core concrete remained close to the average air temperature with minimal 
TABLE 1: The mechanical and geometrical properties of Zangmu Bridge.

\begin{tabular}{|c|c|c|c|c|c|c|c|}
\hline $\begin{array}{l}\text { Span } \\
(\mathrm{m})\end{array}$ & $\begin{array}{c}\text { Ratio of rise to } \\
\text { span }\end{array}$ & Arch axis & Bridge type & $\begin{array}{l}\text { Arch rib section } \\
(\mathrm{mm})\end{array}$ & $\begin{array}{l}\text { Construction } \\
\text { method }\end{array}$ & $\begin{array}{l}\text { Concrete strength of } \\
\text { arch rib }\end{array}$ & Remarks \\
\hline 430 & $1 / 3.8$ & $\begin{array}{l}\text { Catenary } \\
m=1.85\end{array}$ & $\begin{array}{l}\text { Half- } \\
\text { through }\end{array}$ & $1800 \times 42$ & Cableway erection & C60 & $\begin{array}{l}\text { Inclined } \\
\text { arch }\end{array}$ \\
\hline
\end{tabular}

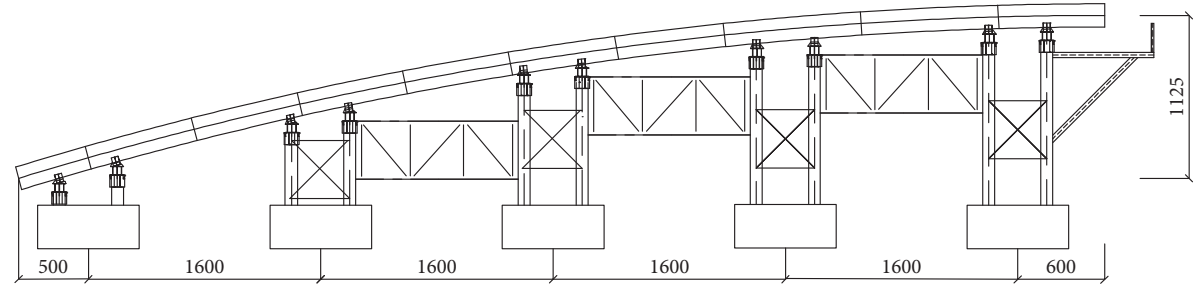

(a)

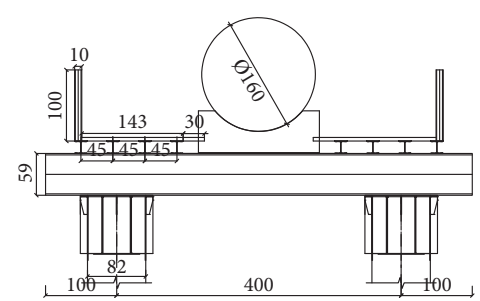

(b)

Figure 1: (a) Main view of the test arch (unit: $\mathrm{cm}$ ). (b) Side view of the test arch (unit: $\mathrm{cm}$ ).

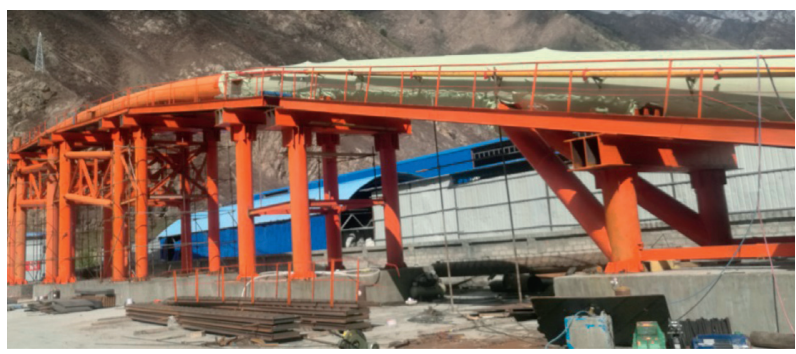

FIgURE 2: Photograph of the test arch.

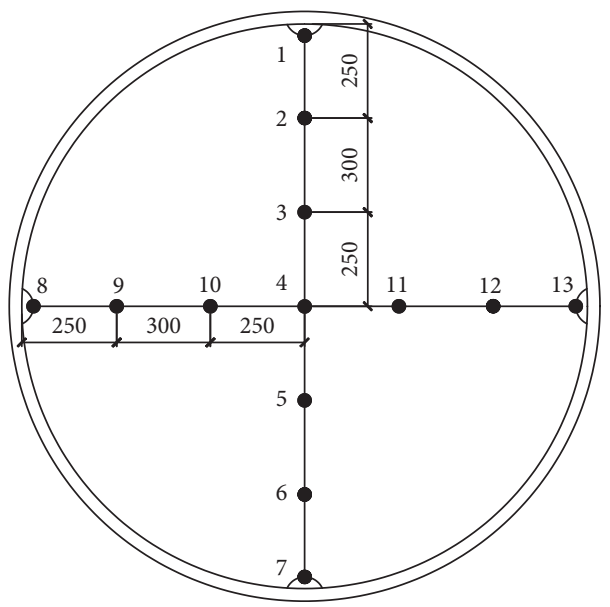

(a)

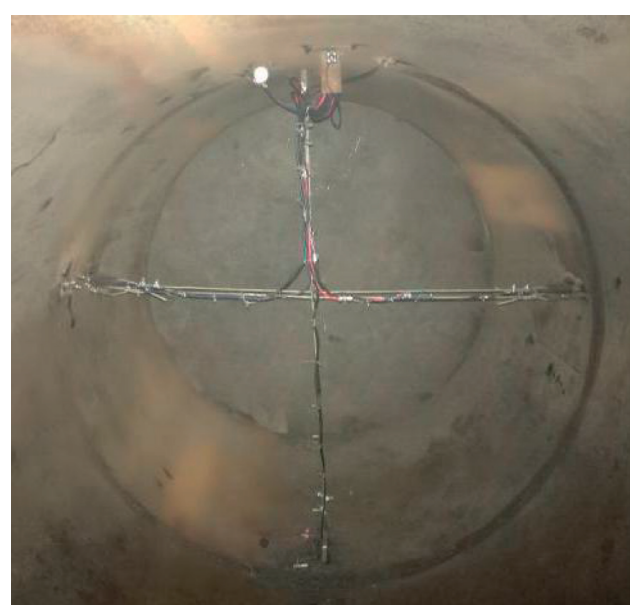

(b)

Figure 3: (a) Schematic of the temperature measurement points installed in the test arch (unit: mm). (b) Photograph of the temperature measurement points installed in the test arch.

fluctuations. The concrete near the edge of the pipe wall was greatly affected by environmental factors, following the daily fluctuations in the air temperature. The results show that the average temperature of the test arch was $16.5^{\circ} \mathrm{C}$ on the seventh day after pouring, when the average air temperature was $14.0^{\circ} \mathrm{C}$.

According to Code 1, the formula for the closure temperature is as follows:

$$
T=T_{28}+\frac{D-0.85}{0.2}+T_{a}
$$

where $T_{28}$ is the average air temperature within a 28-day period after concrete pouring $\left({ }^{\circ} \mathrm{C}\right) ; D$ is the outer diameter of the steel tube $(\mathrm{m})$; and $T_{a}$ is the temperature added value. According to previous literature [12], this formula is applicable throughout China. Code 2 specifies that the closure 


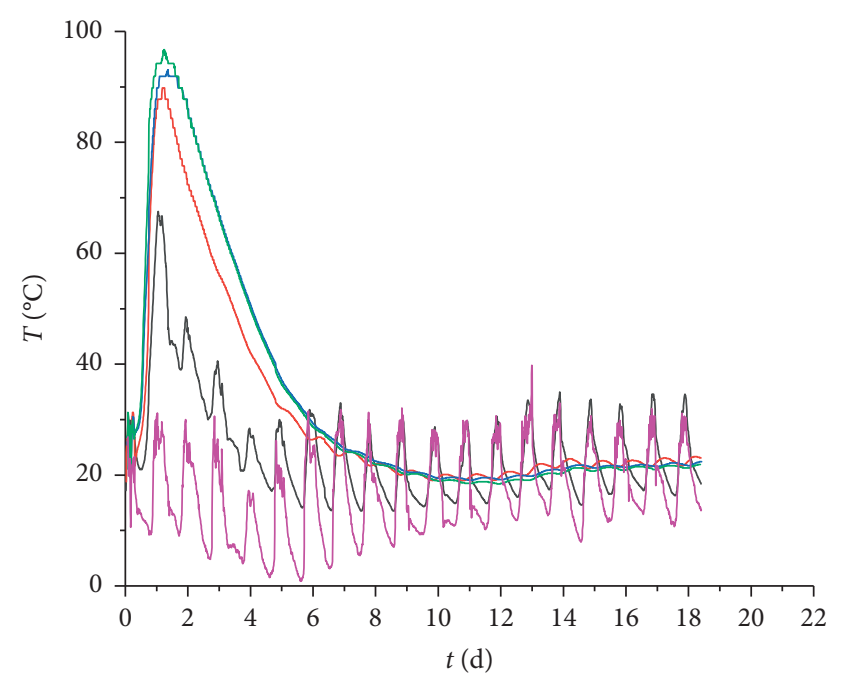

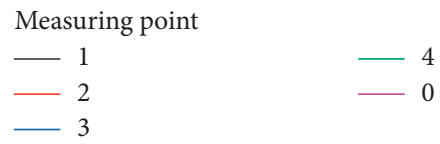

Figure 4: Hydration heat versus time after concrete pouring for the in-pipe concrete.

temperature is the ambient temperature at the time when the main arch steel pipe section was closed and the arch was formed [13], which is calculated as follows:

$$
T=T_{s t}-\frac{\left(T_{s t}-T_{0}\right) E_{s} I_{s}+I_{c} \sum \Delta T_{i} E_{c i}}{\left(E_{s} I_{s}+E_{c} I_{c}\right)},
$$

where $T_{0}$ is the closure temperature of the empty steel tube; $T_{s t}$ is the structural temperature, which corresponds to the average ambient temperature within a 7 -day period after concrete pouring; $E_{s}$ is the elastic modulus of the steel tube; $I_{s}$ is the inertia moment of the steel tube section; $E_{c}$ is the elastic modulus of the concrete; $I_{c}$ is the inertia moment of the concrete section; $\Delta T_{i}$ is the temperature change in each time interval from $T_{h}$ to $T_{s t}$, divided into $n$ segments; $T_{h}$ is the maximum temperature of the structural hydration heat; and $E_{c i}$ is the average elastic modulus of each section in each time interval from $T_{h}$ to $T_{s t}$, divided into $n$ segments.

During the process of concrete pouring in a CFST arch bridge, the concrete does not gain strength immediately after pouring is completed; thus, the concrete gravity is borne solely by the steel pipe. Concrete strength gradually forms with time; however, its gravity is still borne by the arch rib steel tube, and the concrete in the tube is in a low stress state. The closure temperature is typically determined by the temperature of the concrete in the pipe when the concrete strength forms. In this study, the average temperature of the concrete over a one-week period after concrete pouring was designated as test value 1 , and the average temperature of concrete over a one-week period after strength formation (3 days after pouring) was designated as test value 2 . These values are compared with existing research results in Table 1. In addition, the finite element model (FEM) proposed in $[8,12]$ was used to model the closure temperature. The temperature load obtained from the tests was applied to the
FEM in sections to calculate the accumulated internal temperature force. Then, the final temperature and internal temperature force were used to calculate the closure temperature with an internal force of zero (Table 2).

According to the closure temperature calculated by the FEM, the values of closure temperature derived by Code 2 and [9] are underestimated as they do not consider the effect of increased hydration heat on closure temperature. The formula used in [13] enhances the influence of hydration heat, resulting in a higher closure temperature. However, it also involves several parameters, employs complicated calculations, and is not easily applicable to engineering. Test value 1 is much larger than the FEM calculation value, whereas test value 2 is the closest to the FEM calculation value (Code 1 is also found to give a close estimate). Therefore, the average temperature of concrete over a oneweek period after the formation of concrete strength (three days after pouring) is considered the most reasonable value for the closure temperature. Moreover, as Code 1 formula is simple and close to the FEM calculation value, it is considered to be the most applicable of the existing sources.

3.2. Effective Temperature. The maximum and minimum average temperatures of the test arch occurred in August 2018 and January 2019. The temperature variations throughout these months are shown in Figure 5. And by analysing the data, the representative measuring point temperatures of the hottest and coldest two months in a year are obtained in Table 3. The maximum air temperature difference between day and night occurred on January 18, 2019. The maximum atmospheric temperature on January 18,2019 , was $22.7^{\circ} \mathrm{C}$. The minimum atmospheric temperature was $-6.1^{\circ} \mathrm{C}$. The maximum temperature difference between day and night was $33.8^{\circ} \mathrm{C}$ on January 18, 2019 .

The recommended values of effective temperature in codes of China are the local maximum and minimum air temperature; however, these values differ in previous literature. The measured temperatures of the test arch are listed in Table 4. The daily average temperatures on extreme temperature days are the closest to the test value, whereas all other temperature values exhibit substantial differences from the test value. Therefore, it is suggested that the effective temperature should be the local daily average of the highest and lowest air temperature values. As the temperature difference in Tibet is large, if the effective temperature is determined according to the China design codes, the influence of the temperature effect will be overestimated.

3.3. Gradient Temperature. The days with the maximum and minimum temperatures in the test arch were August 7, 2018, and January 18, 2019. The temperature changes throughout these days are shown in Figure 6 and Table 5. The temperature of core concrete was close to the average air temperature, and the temperature of edge concrete varied drastically with the atmospheric temperature. The air temperature peaked around 2:00 p.m., corresponding to the largest temperature difference between the inside and outside of the CFST. 
TABle 2: Comparison of closure temperatures derived from China design codes, previous literature, the field tests, and finite element modelling (values shown in ${ }^{\circ} \mathrm{C}$ ).

\begin{tabular}{lccccccc}
\hline Source & Code 1 & Code 2 & Reference [9] & Reference [13] & Test value 1 & Test value 2 & FEM calculation \\
\hline Closure temperature & 23.5 & 16.5 & 14.0 & 26.4 & 29.6 & 26.1 & 25.3 \\
\hline
\end{tabular}
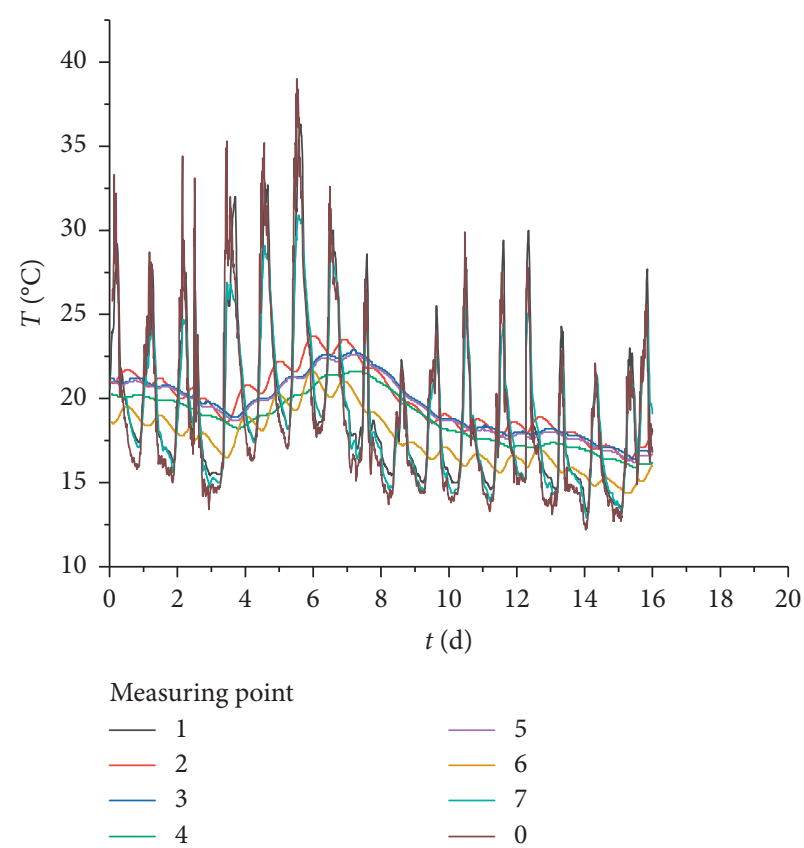

(a)

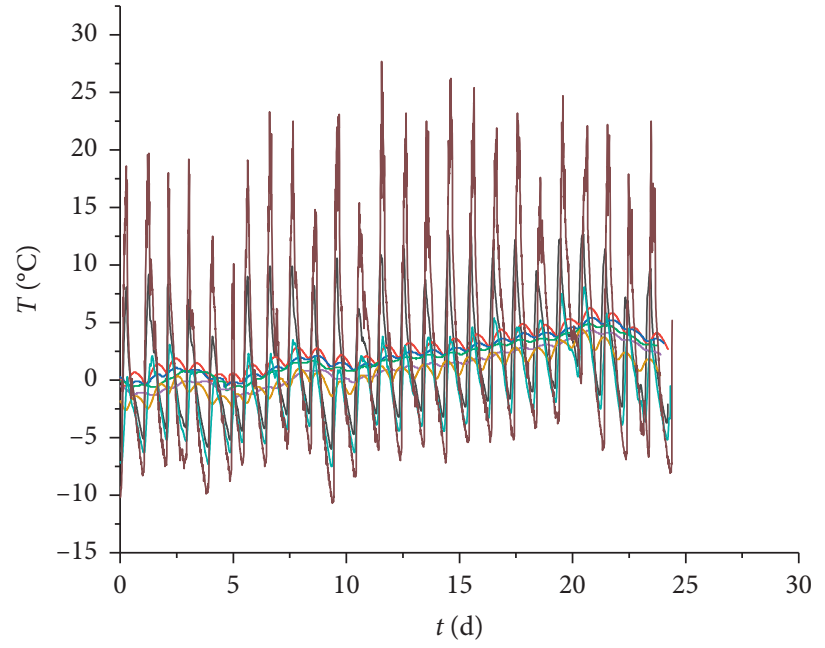

Measuring point

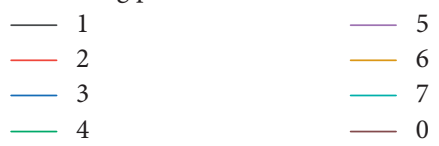

(b)

Figure 5: (a) Temperature changes in the in-pipe concrete over the month of August 2018. (b) Temperature changes in the in-pipe concrete over the month of January 2019.

TABle 3: Temperature measurements at representative points in the test arch in August 2018 and January $2019\left({ }^{\circ} \mathrm{C}\right)$.

\begin{tabular}{|c|c|c|c|c|c|c|c|c|}
\hline Date & & & & & & Jan & & \\
\hline Measurement point & 0 & 1 & 4 & 7 & 0 & 1 & 4 & 7 \\
\hline Maximum temperature & 38.7 & 36.3 & 21.6 & 30.9 & 27.7 & 12.9 & 4.9 & 8.1 \\
\hline Minimum temperature & 12.2 & 13.3 & 15.9 & 12.9 & -10.7 & -6.2 & -0.9 & -7.5 \\
\hline Average temperature & 19.0 & 19.5 & 18.8 & 19.1 & 2.6 & 1.9 & 1.9 & -0.7 \\
\hline
\end{tabular}

TABLE 4: Effective temperature values $\left({ }^{\circ} \mathrm{C}\right)$.

\begin{tabular}{|c|c|c|c|c|c|c|c|}
\hline Date & $\begin{array}{l}\text { Maximum average } \\
\text { temperature }\end{array}$ & $\begin{array}{l}\text { Minimum average } \\
\text { temperature }\end{array}$ & $\begin{array}{c}\text { Average } \\
\text { temperature }\end{array}$ & $\begin{array}{l}\text { Maximum } \\
\text { temperature }\end{array}$ & $\begin{array}{l}\text { Minimum } \\
\text { temperature }\end{array}$ & $\begin{array}{l}\text { Daily average } \\
\text { temperature }\end{array}$ & $\begin{array}{c}\text { Test } \\
\text { results }\end{array}$ \\
\hline Aug 2018 & 27.0 & 14.5 & 19.0 & 38.7 & 12.2 & 24.5 & 23.9 \\
\hline Jan 2019 & 20.7 & -6.8 & 2.6 & 27.7 & -10.7 & -1.7 & -1.4 \\
\hline
\end{tabular}

The standard vertical temperature gradient curve for the main arch's single-pipe section according to Code 2 is shown in Figure 7, and the temperature values are provided in Table 6. The corresponding results from the test arch are shown in Figure 8. The influence range of sunshine temperature, $d$, was found to be $25 \mathrm{~cm}$. The summer and winter gradient temperature values for $T_{1}$ and $T_{2}$ are $16^{\circ} \mathrm{C}$ and $10^{\circ} \mathrm{C}$ and $10^{\circ} \mathrm{C}$ and $3^{\circ} \mathrm{C}$, respectively.
From a comparison of Figures 7 and 8, it is clear that the influence range of gradient temperature is different for Code 2 and the test arch. To obtain an accurate temperature gradient influence range, experimental values from the literature are given in Table 7. The influence range of the sunshine gradient temperature was found to be fixed. Under safety consideration, maximum temperature gradient influence range $d=0.25 \mathrm{~m}$. Comparing Table 8 with Table 6 , 

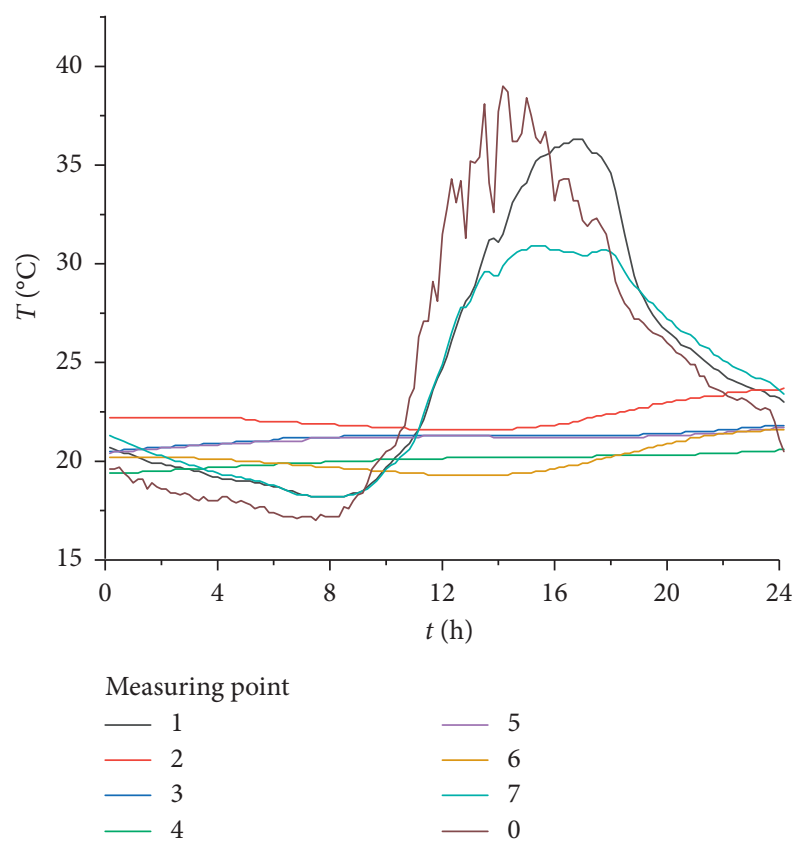

(a)

Figure 6: (a) Temperature changes of the in-pipe concrete on August 7, 2018. (b) Temperature changes of the in-pipe concrete on January $18,2019$.
TABLE 5: Temperature measurements at representative points in the test arch on August 7, 2018, and January 18, $2019\left({ }^{\circ} \mathrm{C}\right)$.

\begin{tabular}{lccccccccc}
\hline Date & \multicolumn{4}{c}{ August } & 7,2018 & \multicolumn{5}{c}{ January } & 18,2019 \\
\hline $\begin{array}{l}\text { Measurement } \\
\text { point }\end{array}$ & 0 & 1 & 4 & 7 & 0 & 1 & 4 & 7 \\
$\begin{array}{l}\text { Maximum } \\
\text { temperature }\end{array}$ & 38.7 & 36.3 & 20.6 & 28.1 & 27.7 & 10.9 & 1.3 & 3.8 \\
$\begin{array}{l}\text { Minimum } \\
\text { temperature }\end{array}$ & 17.0 & 18.2 & 19.4 & 18.2 & -6.1 & -2.9 & 0.8 & -3.9 \\
$\begin{array}{l}\text { Average } \\
\text { temperature }\end{array}$ & 24.5 & 24.5 & 20.11 & 23.9 & 4.2 & 2.6 & 1.1 & -0.1 \\
\hline
\end{tabular}

the test value was approximately $4^{\circ} \mathrm{C}$ higher than the standard value. Therefore, it is suggested that the values in Table 8 are used to calculate the vertical temperature gradient for a single pipe main arch section in the Jiacha area of Shannan, Tibet.

3.4. Thermal Effects. In the design of Chinese arch bridges, FEM calculations are typically used to verify the thermal effects.

In this paper, the whole bridge model of Zangmu Bridge was established by the finite element software ANSYS. When ANSYS is used to model CFST arch bridge, beam element is usually used to simulate CFST arch rib. The beam element in ANSYS is divided into many kinds of elements with different characteristics. It is a kind of $3 D$ element with axial tension, compression, bending, and torsion. Compared with the solid element, the beam element can be solved more efficiently. Among them, BEAM 189 unit provides excellent section data definition function and visual characteristics, which can
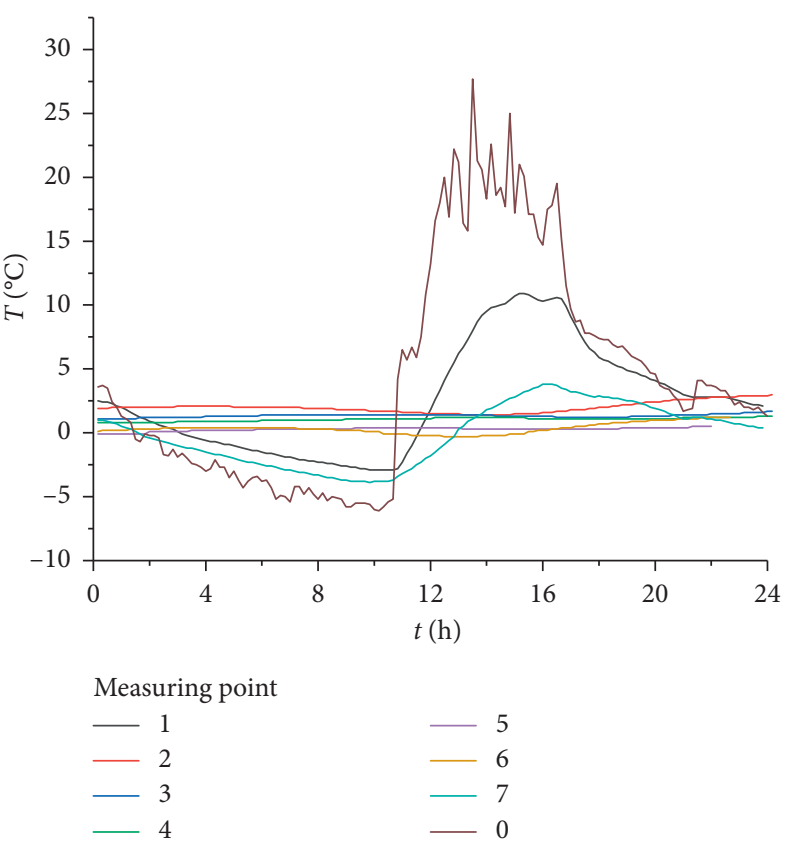

(b)

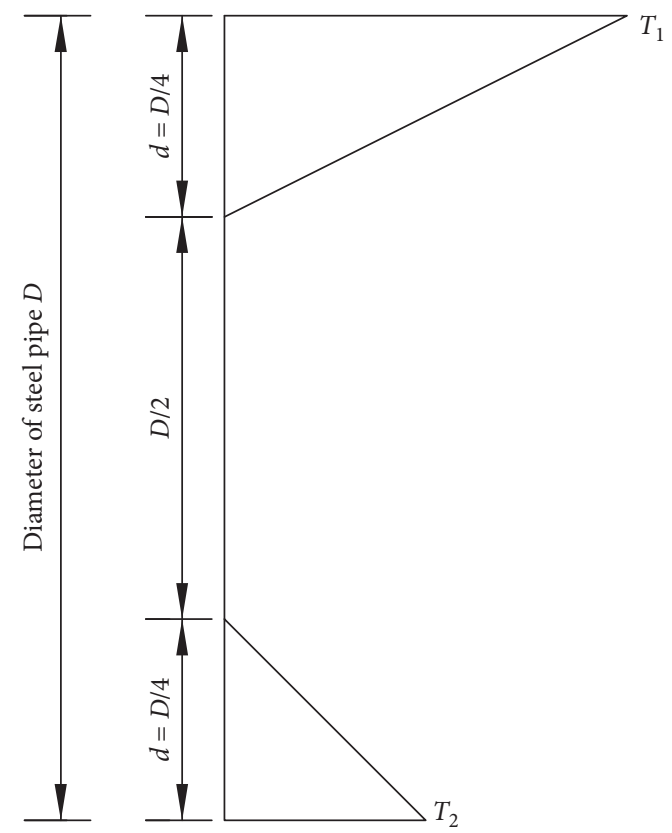

Figure 7: Standard temperature gradient curve used in Code 2.

TABLE 6: Temperature values for $T_{1}$ and $T_{2}$ in Code 2 for different steel pipe coating colours $\left({ }^{\circ} \mathrm{C}\right)$.

\begin{tabular}{lcc}
\hline & \multicolumn{3}{c}{ Single pipe main } \\
Colour of steel pipe surface coating & \multicolumn{3}{c}{ arch } \\
& $T_{1}$ & $T_{2}$ \\
\hline Dark (e.g., red, grey) & 12 & 6 \\
Light (e.g., white, silver) & 8 & 6 \\
\hline
\end{tabular}




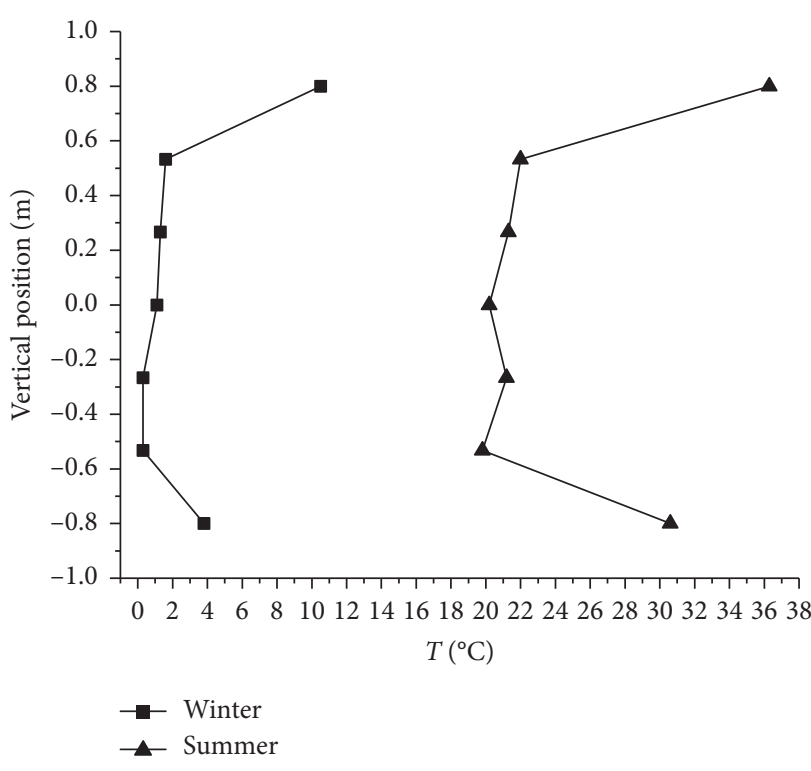

(a)

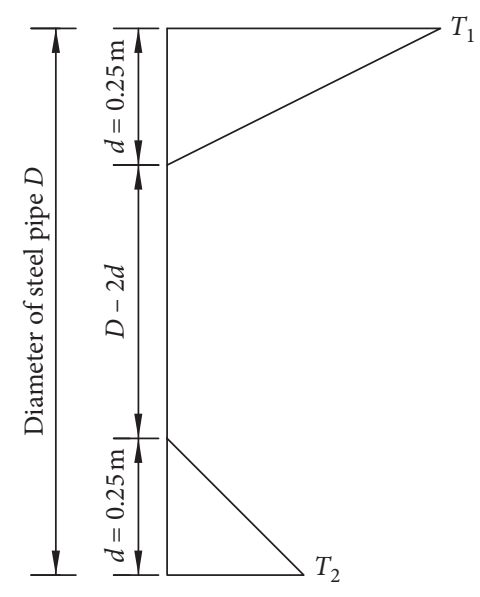

(b)

FIgURE 8: (a) Test gradient temperature. (b) The temperature gradient curve employed in this study.

TABLE 7: Experimental values of the temperature gradient influence range from the literature compared to this study $(\mathrm{m})$.

\begin{tabular}{lcccc}
\hline Literature & {$[14]$} & {$[15]$} & {$[16]$} & $\begin{array}{c}\text { This } \\
\text { study }\end{array}$ \\
\hline $\begin{array}{l}\text { Diameter of steel pipe, } D \\
\begin{array}{l}\text { Temperature gradient influence } \\
\text { range, } d\end{array}\end{array}$ & 0.426 & 0.53 & 0.8 & 1.6 \\
\hline
\end{tabular}

TABle 8: Temperature values for $T_{1}$ and $T_{2}$ in Jiacha, Tibet, for different steel pipe coating colours $\left({ }^{\circ} \mathrm{C}\right)$.

\begin{tabular}{lcc}
\hline & \multicolumn{2}{c}{$\begin{array}{c}\text { Single pipe } \\
\text { Colour of steel pipe surface coating }\end{array}$} \\
& $T_{1}$ & $T_{2}$ \\
\hline Dark (e.g., red, grey) & 16 & 10 \\
Light (e.g., white, silver) & 12 & 10 \\
& \multicolumn{2}{c}{$D<0.5 \mathrm{~m}:$} \\
Temperature gradient influence range, $d$ & $d=D / 2$ \\
& $D>0.5 \mathrm{~m}:$ \\
& $d=0.25 \mathrm{~m}$ \\
\hline
\end{tabular}

customize the section shape of the beam and define different material characteristics in the section. BEAM 189 was used to simulate the CFST arch rib, main beam, web member, transverse brace, and other transverse connection components. LINK 10 was used to simulate the suspender. And SOLID 65 was used to simulate the arch base. In this simulation, the materials were supposed to behave nonlinearly, and Drucker-Prager criterion had been considered $[17,18]$. To implement a nonlinear analysis, the NewtonRaphson algorithm was used, and the displacement criterion was also applied to assess the problem's convergence [19].

However, the conventional model only considers the upper structure, which is constrained by the arch foot, whereas the lower structure including the arch base of the arch bridge also bears the temperature load and stress. Therefore, ANSYS software was used to build two FEMs: a model of the bridge constrained by the arch foot (model 1) and a model of the entire bridge model including the arch base and constrained by the arch base (model 2) (Figure 9). FEM simulations were then conducted using the temperature parameters given in Codes 1 and 2, as well as those proposed in this study, to determine the maximum tensile stress on the arch rib. The results are shown in Figures 10-12.

Concrete has good compression performance and poor tensile performance; thus, it is important to analyse the tensile stress of the arch rib. Figures 10-12 indicate that, under the standard uniform temperature values given in the China design codes and the recommended temperature value proposed in this study, both the steel tube and concrete exhibit large tensile stress at the arch foot. Moreover, the tensile stress at the arch foot under decreasing temperature conditions is much greater than that under increasing temperature conditions. Using the standard uniform temperature load of Codes 1 and 2, the stress of the arch foot steel tube in model 2 is $37.3 \mathrm{MPa}$ when cooled, which is $43.74 \%$ lower than that in model $1(66.3 \mathrm{MPa})$, and the stress of the arch foot concrete when cooled is $2.95 \mathrm{MPa}$, which is $53.4 \%$ lower than that in model $1(6.33 \mathrm{MPa})$. Conversely, using the temperature parameters calculated in this study, the stress of the steel tube at the arch foot in model 2 is 27.1 MPa, which is $43.9 \%$ lower than that in model 1 $(48.3 \mathrm{MPa})$, and the stress of the concrete at the arch foot is $2.15 \mathrm{MPa}$, which is $53.36 \%$ lower than that in model 1 (4.61 MPa). In conclusion, the tensile stress of the arch foot is consistently more than $40 \%$ smaller using model 2 .

Under increasing temperature conditions, the arch rib only experiences a low stress; therefore, it is more important to focus on the conditions of decreasing temperature. 


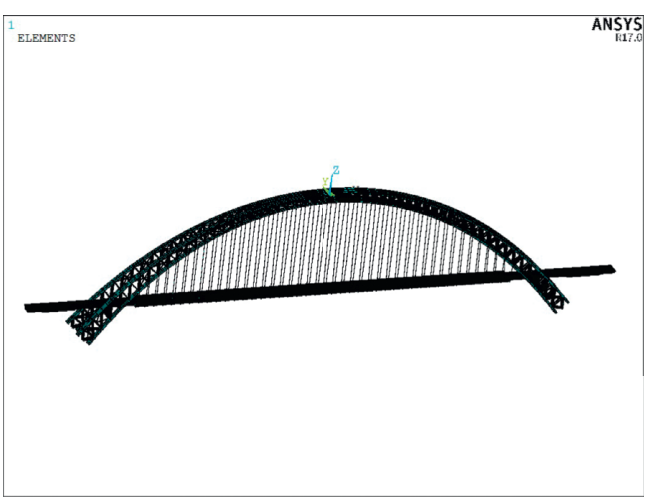

(a)

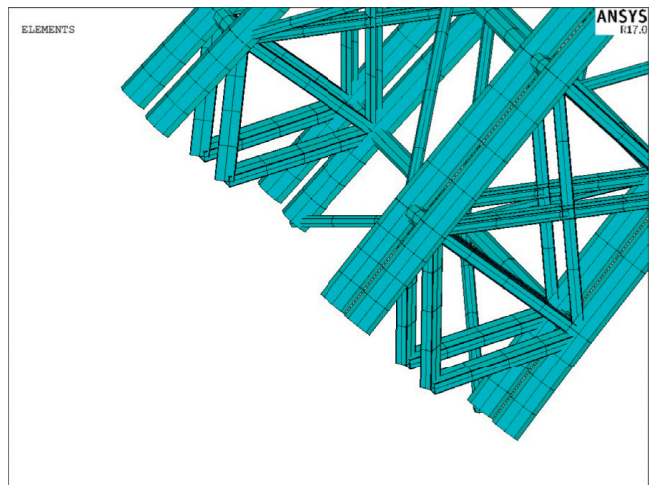

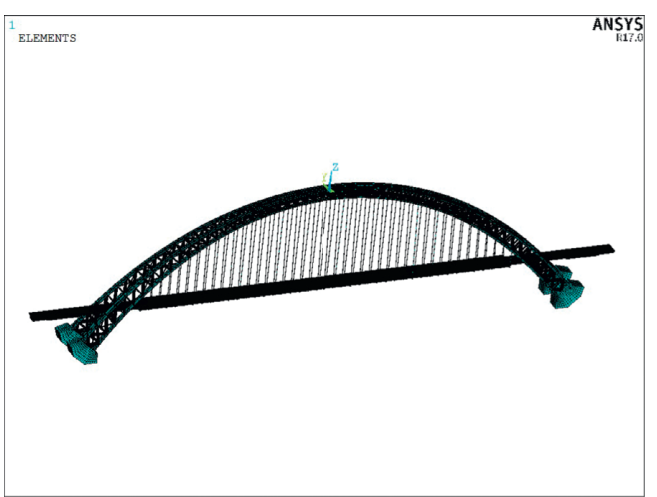

(b)

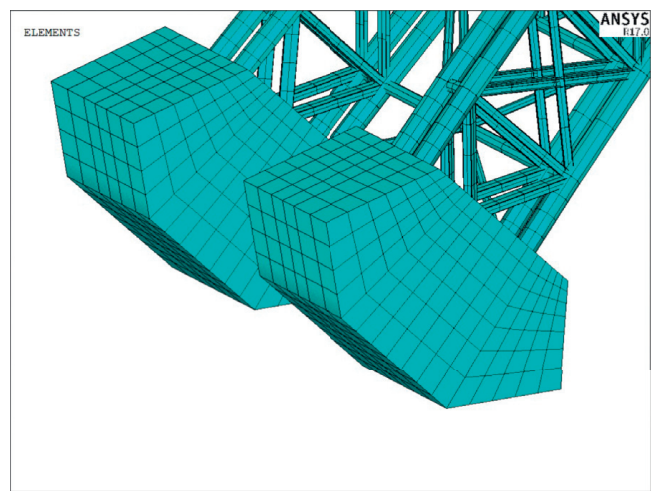

(c)

FIGURE 9: (a) Finite element model conventional simulation (model 1). (b) Finite element model including the arch base (model 2). (c) Details of arch foot in model 1. (d) Details of arch foot in model 2.

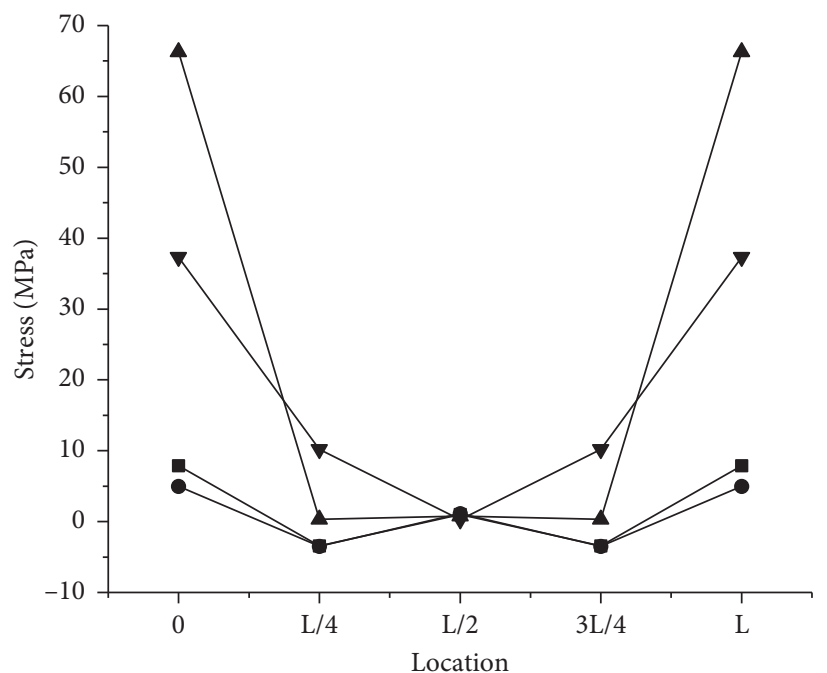

Temperature rise

$\rightarrow$ Model 1

$\longrightarrow$ Model 2

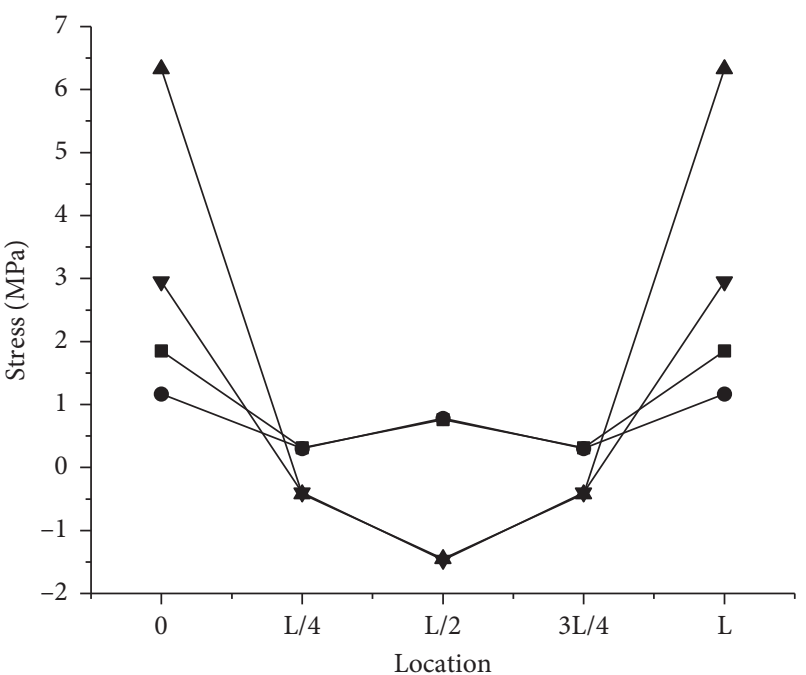

Temperature rise

$\longrightarrow$ Model 1

$\longrightarrow$ Model 2
Temperature drop

$\longrightarrow$ Model 1

(b)

Figure 10: (a) Maximum tensile stress of arch rib steel tube under the uniform temperature load of Codes in China. (b) Maximum tensile stress of arch rib concrete under the uniform temperature load of Codes in China. 


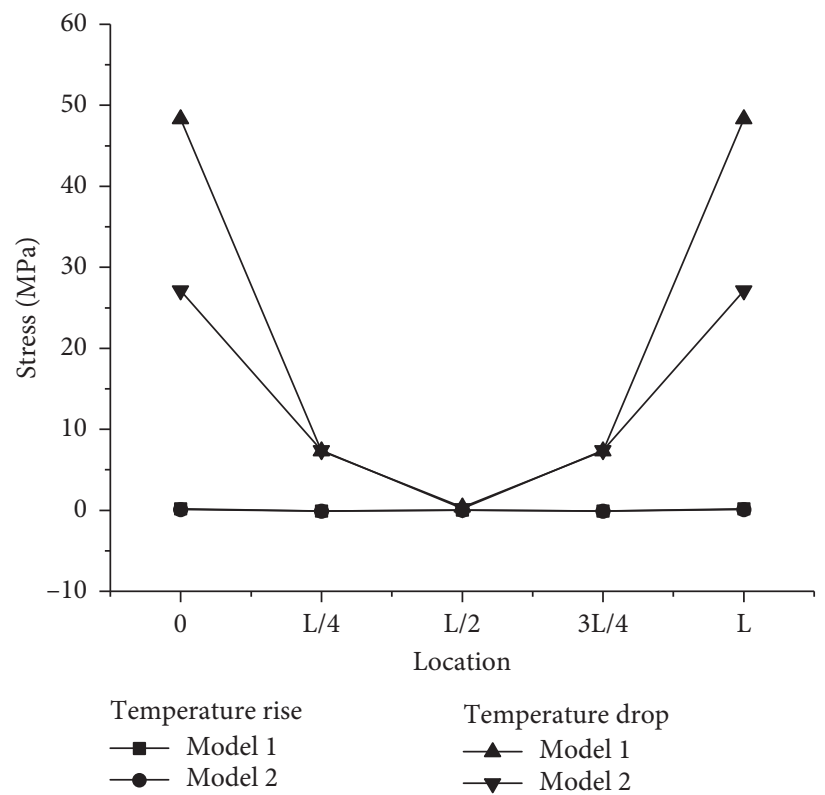

(a)

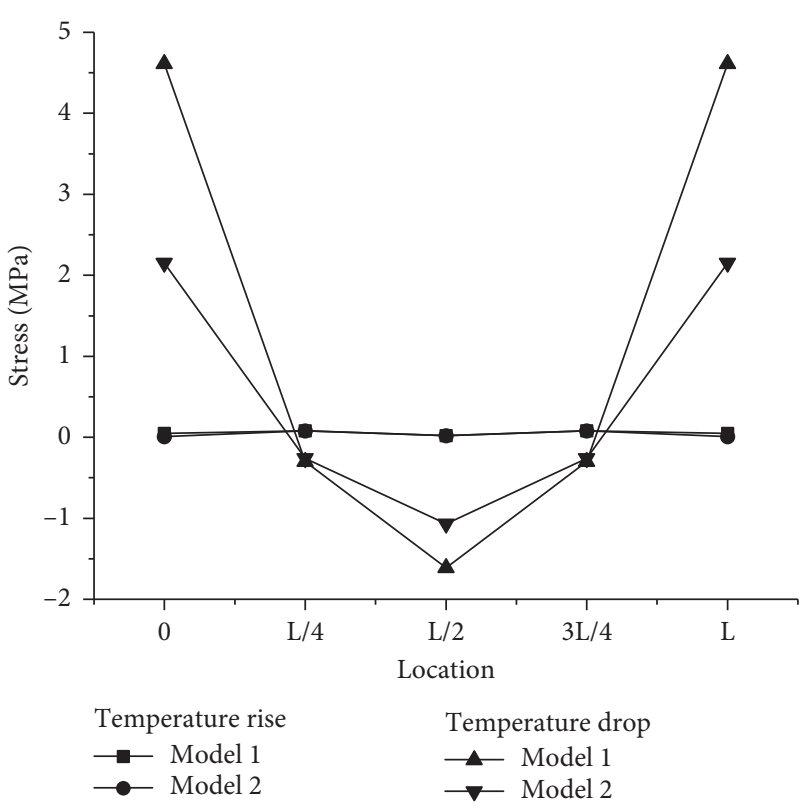

(b)

Figure 11: (a) Maximum tensile stress of arch rib steel tube under the uniform temperature loads measured in this study. (b) Maximum tensile stress of arch rib concrete under the uniform temperature loads measured in this study.

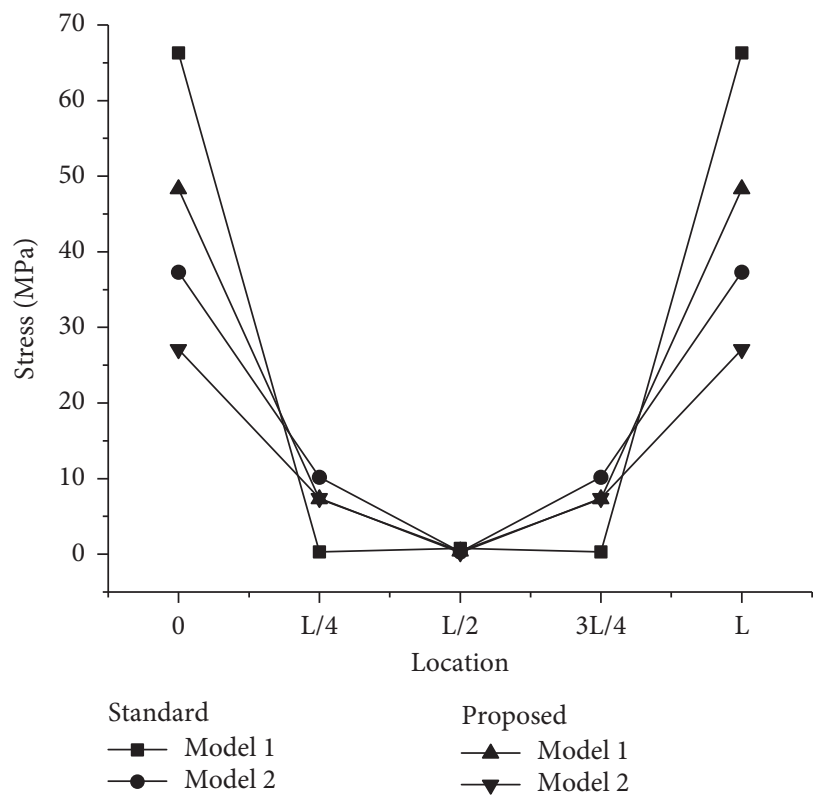

(a)

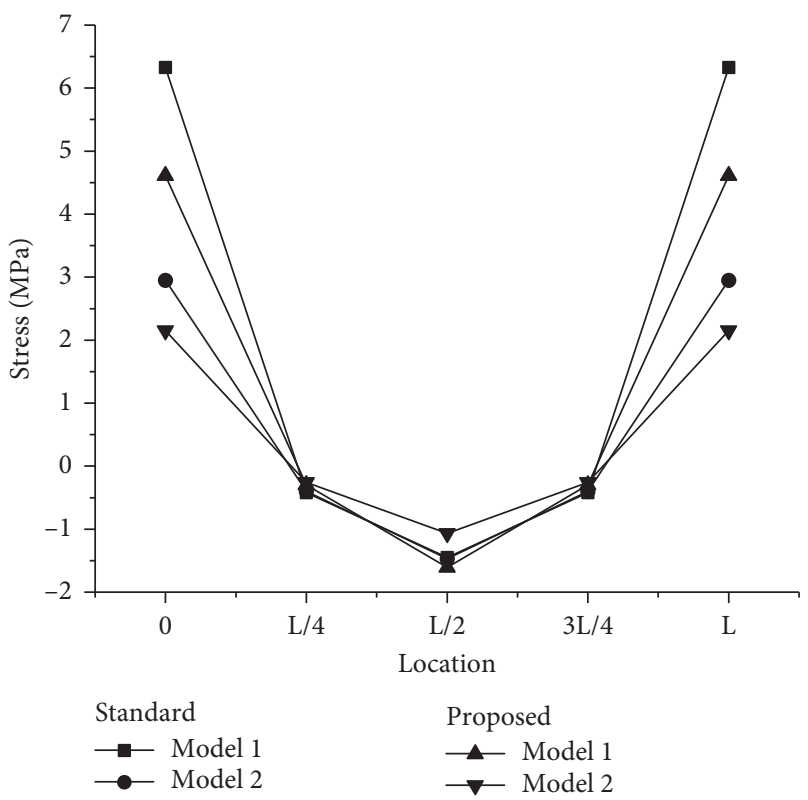

(b)

FIGURE 12: (a) Maximum tensile stress of arch rib steel tube under cooling conditions. (b) Maximum tensile stress of arch rib concrete under cooling conditions.

Figure 12 shows that, during cooling, the stress values for both the arch foot steel pipe and concrete are approximately $27 \%$ lower when using the temperature values determined in this study instead of the standard temperature values proposed in Codes 1 and 2 for both model 1 and model 2 .

The difference in the stress produced by the uniform temperature load in the refined model (model 2) compared with the conventional model (model 1) is more than $40 \%$. In the test bridge, the arch foot is connected to the arch base and foundations; thus, the entire bridge structure is affected by the uniform temperature load. Thus, our results demonstrate that the refined model more accurately reflects the actual temperature effects. Furthermore, the difference in the stress calculated using the temperature values proposed in 
this study compared with the standard temperature values of the China design code is more than $25 \%$. Therefore, calculating the stress using the standard temperature values will result in an overestimate, particularly of the tensile stress of the arch foot concrete. Conversely, the temperature parameters recommended in this study were obtained from actual test data; thus, they are more applicable to engineering projects. Therefore, when verifying the thermal effects in the design of CFST arch bridges, we suggest employing a refined FEM model that includes the arch base as well as the temperature parameters proposed in this study.

\section{Conclusion}

A long-term continuous field test was conducted to measure the temperature of a test arch in Tibet and determine the calculation parameters that describe the temperature load and thermal effect of a bridge under these temperature conditions. The following conclusions were obtained:

(1) The maximum and minimum average temperatures in Jiacha County, Shannan City, Tibet, were $19^{\circ} \mathrm{C}$ and $2.6^{\circ} \mathrm{C}$, respectively, and the maximum temperature difference between day and night was $33.8^{\circ} \mathrm{C}$. Therefore, this area is characterised by a low average temperature and a large diurnal and annual temperature difference.

(2) To calculate the closure temperature of a large-diameter CFST arch bridge in the Jiacha area, it is not suitable to use the average air temperature plus the additional temperature of hydration heat. Alternatively, the average temperature of concrete in the pipe after the concrete strength has formed (three days after pouring) should be used. However, the formula suggested in the China Technical Code for CFST Arch Bridges (GB 50923-2013) is still considered applicable.

(3) The effective temperature of a large-diameter CFST arch bridge in the Jiacha area of Tibet should not be calculated using the extreme air temperature or monthly average air temperature, which differed considerably from the test value. Alternatively, we recommend using the daily average temperature of extreme temperature days.

(4) The calculation parameters for the vertical temperature gradient of a single pipe given in the China Highway Design Code for CFST Arch Bridges (JTGT-D65-06-2015) are not applicable in the study area. It is suggested that when the diameter of the steel pipe $(D)$ is less than $1 \mathrm{~m}$, the temperature gradient influence range is $D / 2$. Conversely, when $D$ is greater than $1 \mathrm{~m}$, the temperature gradient influence range is $25 \mathrm{~cm}$. Moreover, according to the test results, we suggest increasing the values of the vertical gradient temperature in a single pipe by $4^{\circ} \mathrm{C}$.

(5) The maximum stress calculated by the refined finite element model, which included the arch base, was at least $40 \%$ smaller than that calculated by the conventional model. In addition, the arch foot stress calculated using the temperature parameters proposed in this study was at least 25\% smaller than that calculated using those recommended in the China design codes. Therefore, when verifying the thermal effects during CFST arch bridge design, we suggest employing the refined FEM and the temperature parameters proposed in this study.

\section{Data Availability}

The data used to support the findings of this study are included within the supplementary information files.

\section{Disclosure}

The funders had no role in the design of the study; in the collection, analyses, or interpretation of data; in the writing of the manuscript; or in the decision to publish the results.

\section{Conflicts of Interest}

The authors declare no conflicts of interest.

\section{Acknowledgments}

The authors would like to thank China Railway Guangzhou Engineering Group Co., Ltd, for the materials used for experiments and Editage (http://www.editage.cn) for the English language editing. This research was funded by the National Natural Science Foundation of China (Grant nos. 51738004, 51868006, and 51878186), by The Major Science and Technology Foundation of Guangxi (Grant no. AA18118029), and by Project of Science and Technology Research and Development Plan of China Railway Corporation (2017G006-b).

\section{Supplementary Materials}

Supplementary Figure 4: closure temperature analysis. Supplementary Figure 5: effective temperature analysis. Supplementary Figures 6 and 8: gradient temperature analysis. Supplementary Figures 10-12: thermal effects analysis. (Supplementary Materials)

\section{References}

[1] J. L. Zheng, "Development and prospect of long-span arch bridge," China Highway, vol. 22, pp. 41-42, 2017.

[2] J. Zheng and J. Wang, "Concrete-filled steel tube Arch bridges in China," Engineering, vol. 4, no. 1, pp. 143-155, 2018.

[3] J. L. Zheng, J. J. Wang, Z. Feng et al., "Vacuum assisted technology test of CFST arch," Journal of China Highway, vol. 27, no. 6, pp. 44-50, 2014.

[4] Y. J. Liu, J. Liu, and N. Zhang, "Summary of the effect of sunshine temperature on bridge structure," Journal of Civil Engineering, vol. 52, no. 5, pp. 59-78, 2019.

[5] GB 50923-2013, CFST Arch Bridge Technical Code in China.

[6] JTG/TD 65-06-2015, Highway CFST Arch Bridge Design Code in China. 
[7] B. C. Chen, Y. Lun, and A. M. Xu, "Analysis of the CFST arch bridge temperature inner force composite and hybrid structures," in Proceedings of the 6th ASCCS Conference on Steel and Concrete Composite Structures, pp. 239-246, Los Angeles, CA, USA, March 2000.

[8] B. C. Chen, A. M. Xu, and C. Sun, "Analysis of temperature difference value in calculation of temperature internal force of CFST arch bridge," Journal of China Highway, vol. 13, no. 2, pp. 52-56, 2000.

[9] C. J. Lin, J. L. Zheng, and H. D. Huang, "Experimental study on closure temperature of CFST arch," Journal of Guangxi University (Natural Science Edition), vol. 35, no. 4, pp. 601608, 2010.

[10] F. Y. Huang, B. C. Chen, and T. Ke, "Study on the calculation temperature value of CFST dumbbell arch," Journal of Fuzhou University (Natural Science Edition), vol. 39, no. 2, pp. 266275, 2011.

[11] Z. Y. Liu, C. Sun, and B. C. Chen, "Study on calculation value of temperature difference between CFST truss and Arch," Highway Transportation Technology, vol. 27, no. 12, pp. 86-93, 2010.

[12] J. K. Chen, B. C. Chen, Z. Y. Liu, and X. M. Yu, "Study on the design value of uniform temperature difference of CFST arch," Journal of Civil Engineering and Management, vol. 30, no. 4, pp. 1-7, 2013.

[13] B. Yang, J. Huang, C. Lin, and X. Wen, “Temperature effects and calculation method of closure temperatures for concretefilled steel tube Arch rib of dumbbell-shape section," The Open Civil Engineering Journal, vol. 5, no. 1, pp. 179-189, 2011.

[14] L. Jiang, Y. J. Liu, and G. J. Zhang, "Experimental analysis of temperature gradient patterns of concrete-filled steel tubular members," Journal of Bridge Engineering, vol. 24, no. 11, Article ID 04019109, 2019.

[15] K. Chen and Y. D. Li, "Test and finite element calculation of solar temperature field of section of CFST arch rib," Journal of Highway and Transportation Research and Development, vol. 29, no. 9, pp. 77-84, 2012.

[16] W. Yan, Analysis of Temperature Field and Temperature Effect of Concrete-Filled Steel Tubular Arch Rib Section, Chang'an University, Xi'an, China, 2008.

[17] M. Yazdani, V. Jahdngiri, and M. S. Marefat, "Seismic performance assessment of plain concrete arch bridges under near-field earthquakes using incremental dynamic analysis," Engineering Failure Analysis, vol. 106, Article ID 104170, 2019.

[18] A. Moazam, N. Hasani, and M. Yazdani, "Three-dimensional modelling for seismic assessment of plain concrete arch bridges," Proceedings of the Institution of Civil Engineers-Civil Engineering, vol. 171, no. 3, pp. 135-143, 2018.

[19] A. Moazam, N. Hasani, and M. Yazdani, "3D simulation of railway bridges for estimating fundamental frequency using geometrical and mechanical properties," Advances in Computational Design, vol. 2, no. 4, pp. 257-271, 2017. 